\title{
Diagnosis and monitoring of HIV infection
}

Glass AJ, MBChB (UCT), Dip.PEC (SA), DTM\&H (WITS), Dip.HIV MAN (SA)

Department of Medical Virology, University of Pretoria, Tshwane Academic Division, NHLS

Address for correspondence: Dr Allison Glass, e-mail: allison.glass@up.ac.za

(SA Fam Pract 2006;48(8):46)

\section{Abstract}

The latest statistics indicate that the number of people infected with human immunodeficiency virus type 1 (HIV-1) worldwide is 40.3 million, 25.8 million of whom live in sub-Saharan Africa. In 2004, $29.5 \%$ of South African women attending antenatal clinics were infected. The virus infects people of all ages and social classes. A diagnosis of HIV has serious physical, emotional and social implications for the patient. HIV-infected patients are susceptible to numerous opportunistic and other infections, as well as to non-infectious diseases such as tumours. They eventually require lifelong treatment with potentially toxic medication. It is therefore essential that a timeous and correct diagnosis be made.

An understanding of the tests available for the diagnosis and monitoring of HIV is essential for all clinicians working in South Africa. Tests available for the diagnosis of HIV in patients older than 18 months include HIV-specific antibody assays, fourthgeneration combination antibody-antigen assays and Western Blot. The diagnosis of HIV infection in infants younger than 18 months requires detection of the virus itself by means of p24 antigen detection or HIV DNA PCR. The CD4+ T lymphocyte count and HIV viral load are used for monitoring disease progression and response to therapy.

\section{Introduction}

The latest statistics indicate that the number of people infected with human immunodeficiency virus type 1 (HIV-1) worldwide is 40.3 million ${ }^{1}$, of whom 25.8 million live in sub-Saharan Africa. In 2004, $29.5 \%$ of South African women attending antenatal clinics were infected ${ }^{2}$. The virus infects people of all ages and social classes. A diagnosis of HIV has serious physical, emotional and social implications for the patient. HIV infected patients are susceptible to numerous opportunistic and other infections, as well as non-infectious diseases such as tumours. They eventually require lifelong treatment with potentially toxic medication. It is therefore essential that a timeous and correct diagnosis be made.

\section{Back to Basics}

HIV is classified in the genus Lentivirus of the family Retroviridae. There are two species of HIV within the genus: HIV-1 and HIV-2. HIV-1 is responsible for the global pandemic with HIV-2 accounting for infections predominantly confined to West Africa. HIV-1 is further divided into three groups namely $\mathrm{M}, \mathrm{N}$ and $\mathrm{O} . \mathrm{M}$ is responsible for the majority of infections. There are nine subtypes within group $M$, as well as at least 21 different inter-subtype circulating recombinant forms (CRFs) ${ }^{3,4}$.

HIV contains a genome made up of two single strands of RNA. Surrounding the genome is a capsid composed of the p24 protein (antigen). The viral particle is surrounded by a lipoprotein membrane containing glycoproteins, namely gp120 and gp41 (Figure 1). Upon entry into a CD4+ cell, the viral enzyme reverse transcriptase converts the viral RNA into DNA. The viral DNA is transported to the nucleus of the cell where it is integrated into the host DNA. Once integrated the viral DNA is referred to as proviral DNA. HIV thus essentially becomes an acquired genetic disease. Proviral DNA is transcribed to RNA that is then translated into viral proteins. These viral proteins are processed to form new viral particles that bud from the cell membrane and are able to infect new CD4+ cells (Figure 2).

After infection with HIV, the virus replicates to a high viral load (up to millions of copies) prior to the host mounting an immune response. Although the immune response is unable to eradicate the infection, it is able to bring the viral replication under control. This causes the viraemia to decrease until it reaches a viral setpoint i.e. a stable viral load that is maintained until the immune
Figure 1: The structure of HIV

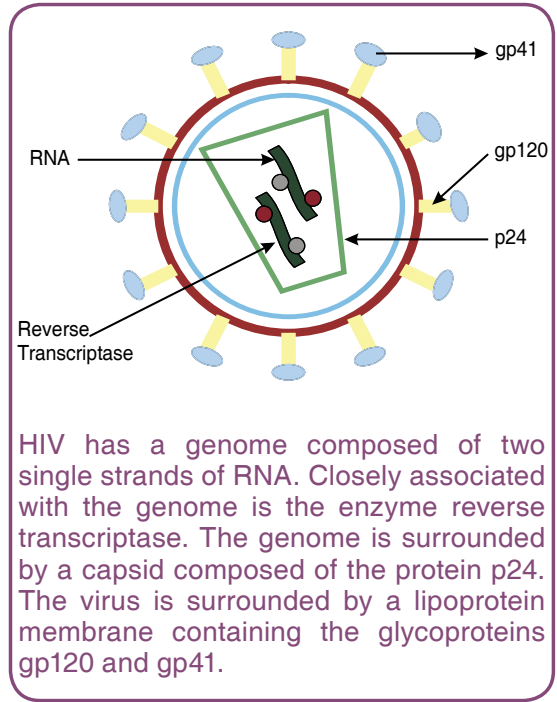

system becomes depleted. The viral setpoint is a strong predictor of the rate of disease progression, i.e. the higher the setpoint, the quicker the disease will progress. Once the immune system becomes exhausted by the ongoing infection, the viral load will once again increase as the CD4+ $\mathrm{T}$ lymphocyte count decreases ${ }^{5}$ (Figure 3 ).

The first detectable marker of infection is HIV RNA. The earliest it can be detected is 11 days post-infection. HIV 
Figure 2: The life cycle of HIV.

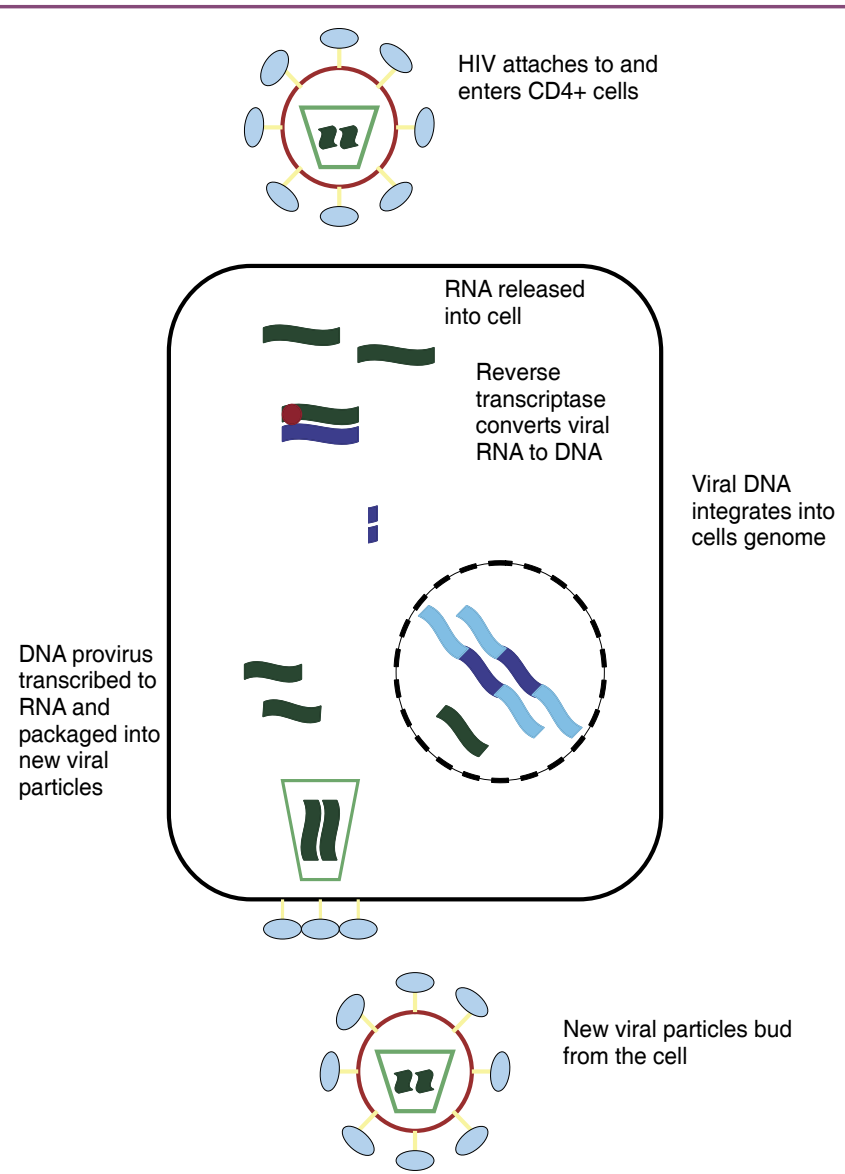

HIV enters a CD4+ cell and its genome is released into the cytoplasm. Reverse transcriptase converts the viral RNA into DNA. The DNA is transferred to the nucleus of the cell where it becomes integrated into the host cell DNA. The integrated/proviral DNA is transcribed to RNA and translated into viral proteins. Viral proteins assemble to form new viral particles that bud from the cell surface.

Figure 3: Immunological markers for HIV

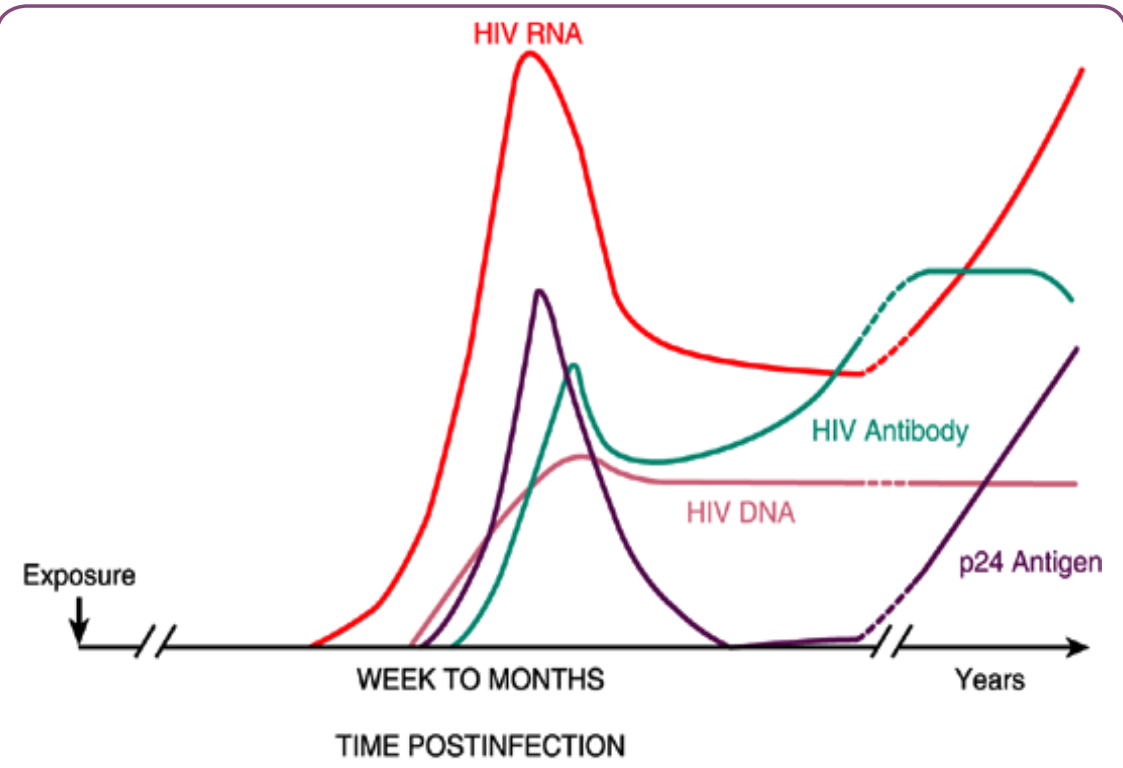

Viral RNA is detectable in the blood from approximately 11 days post-infection. There is a rapid rise in viral RNA levels (viral load) until the immune system responds, after which the RNA levels decrease to a viral set point that is maintained for a prolonged period. HIV DNA and p24 become detectable in the blood from approximately 16 days post-infection. p24 levels then become undetectable until the end stage of disease, at which time p24 levels rise. HIV antibodies are detectable from approximately 24 days post-infection.
DNA and the p24 antigen are detectable from approximately 16 days post-infection. HIV-specific antibodies become detectable at the earliest at 24 days, but a small percentage of individuals may take as long as two months to produce detectable antibodies ${ }^{6}$. The p24 antigen often becomes undetectable once the viral setpoint is reached and only becomes detectable again towards the terminal stages of the disease when the immune system is no longer able to control viral replication.

\section{Diagnosis of HIV in patients older than 18 months of age}

When testing for HIV one needs to consider:

- the sensitivity and specificity of the test

- the ability of the test to detect all stages of infection

- the ability of the test to detect all types and subtypes of the virus

- the cost of the test.

The basis of HIV testing is the detection of HIV-specific antibodies. These are present in virtually $100 \%$ of patients with HIV infection and their presence indicates infection. An ELISA (enzyme linked immunosorbent assay) is the method used to detect antibodies or antigen. Previous assays ( $1^{\text {st }}-3^{\text {rd }}$ generation assays) detected HIV-specific antibodies alone. The $4^{\text {th }}$ generation combination assays that are now available detect HIV-specific antibodies and the p24 antigen simultaneously. This has the advantage of shortening the window period to a minimum of 18 days as well as increasing the detection of HIV in late disease when HIV-specific antibody levels may be low. The assays are also designed in such a way as to detect HIV-1 and HIV-2, as well as the majority of subtypes and CRFs. The present day assays are almost $100 \%$ sensitive and approximately $99.7 \%$ specific for HIV infection ${ }^{7}$. It is essential to do a confirmatory test if the screening test is positive/reactive, in order to exclude false positives. In addition, a second specimen should be sent for repeat testing to avoid any errors, such as mislabelled specimens.

A p24 antigen ELISA on its own should not be used to diagnosis HIV outside the seroconversion phase as it is only $79 \%$ sensitive and, as mentioned earlier, may be negative during a large portion of the disease process ${ }^{8}$. Qualitative HIV RNA and DNA PCRs are available, but are expensive. Their use 
Table I: Tests available for the diagnosis of HIV

\begin{tabular}{|l|l|}
\hline \multicolumn{1}{|c|}{ Test } & \multicolumn{1}{c|}{ Indication } \\
\hline Rapid HIV test & $\begin{array}{l}\text { Immediate result required e.g. emergency situation or patient unlikely } \\
\text { to return for result }\end{array}$ \\
\hline $4^{\text {th }}$ generation HIV ELISA & $\begin{array}{l}\text { Diagnosis of HIV infection in patients }>18 \text { months of age. } \\
\text { Screening for exposure in infants }<18 \text { months of age. }\end{array}$ \\
\hline HIV-specific antibodies & $\begin{array}{l}\text { Diagnosis of HIV infection in patients }>18 \text { months of age. } \\
\text { Screening for exposure in infants }<18 \text { months of age. }\end{array}$ \\
$\left(1^{\text {st }}-3^{\text {rd }}\right.$ generation ELISAs $)$ & $\begin{array}{l}\text { Diagnosis of acute seroconversion. } \\
\text { Diagnosis of HIV infection in patients }<18 \text { months of age }\end{array}$ \\
\hline p24 antigen &
\end{tabular}

Table II: Tests available for monitoring HIV infection

\begin{tabular}{|l|l|}
\hline \multicolumn{1}{|c|}{ Test } & \multicolumn{1}{c|}{ Indication } \\
\hline CD4+ count & $\begin{array}{l}\text { Monitoring of disease progression } \\
\text { Indicator of when to initiate HAART } \\
\text { Monitoring immunological response to therapy }\end{array}$ \\
\hline HIV viral load & $\begin{array}{l}\text { Prognostic indicator } \\
\text { Monitoring virological response to therapy }\end{array}$ \\
\hline
\end{tabular}

is not advised for routine testing due to the availability of reliable, cheaper options.

Western Blot was previously used as a confirmatory test. Antibodies directed against HIV proteins bind to relevant areas on a strip and are detected by the addition of an enzyme-labelled secondary enzyme and substrate. Most laboratories no longer use Western Blot, as it is expensive and labour intensive, and $3^{\text {rd }}$ and $4^{\text {th }}$ generation ELISA assays are more reliable than those previously available. The Western Blot is however a useful tool for differentiating between infections with HIV-1 and HIV-2.

\section{Diagnosis of HIV in patients younger than 18 months of age}

The risk of vertical transmission of HIV from an infected mother to her infant is $15-30 \%$. With intervention, i.e. caesarean section, formula feeding and antiretroviral prophylaxis or HAART (highly active antiretroviral therapy), the risk decreases to less than $2 \% 9$. Maternal HIV-specific antibodies may be detectable in the infant's blood for up to 18 months of age. It is therefore essential to distinguish between passively acquired antibodies and active HIV infection.

If a $4^{\text {th }}$ generation ELISA assay gives a positive/reactive result, it does not distinguish between antibodies and antigen. If a $4^{\text {th }}$ generation assay or any other antibody assay gives a positive/ reactive result, a separate p24 antigen assay should be performed. If the p24 antigen is positive, the infant is infected with HIV. If the p24 antigen is negative, it does not preclude the possibility of infection as mentioned previously.

HIV-1 DNA PCR is the mainstay of HIV-1 diagnosis in infants. The assay detects HIV-1 viral DNA in leukocytes. The South African Department of Health recommends testing the infant at 6 weeks and if negative, again at 4 months ${ }^{10}$. The second test at 4 months of age is necessary to detect infected infants who may have had undetectable levels of HIV-1 DNA at initial testing 11. If there is ongoing exposure e.g. breastfeeding, the test will need to be repeated six weeks after the exposure has ceased. A positive result should be confirmed on a second specimen.

\section{Rapid HIV testing}

A number of rapid tests are available for the detection of HIV-specific antibodies. These tests provide a result within 15-30 minutes. They are of use when a result is required quickly in an emergency situation or at clinics where results are provided immediately to patients who may not return. Rapid tests are not as sensitive or specific as $4^{\text {th }}$ generation assays. Some rapid tests detect HIV-1-specific antibodies only, while others detect HIV-1- and HIV-2specific antibodies. All results obtained by rapid testing should be confirmed as both false positive and false negative results can occur ${ }^{12}$

\section{MONITORING DISEASE PROGRES-} SION AND RESPONSE TO THERAPY Monitoring of HIV-1 infection should not rely on any single marker. The patient's clinical condition needs to be considered in addition to the HIV-1 viral load and the CD4+ T lymphocyte count.

\section{HIV-1 Viral Load}

Quantitative HIV-1 RNA testing (HIV1 viral load) detects and quantifies the HIV-1 RNA in plasma. The viral load is given as a value representing RNA copies per millilitre, as well as a log value, e.g. $100=2 \log , 1000=3$ $\log , 10000=4 \log$ etc. The log value provides an easier number to work with and better indicates significant changes in viral load.

This test serves a number of purposes:

- It determines the viral setpoint and acts as a long-term predictor of prognosis.

- It acts as a guide for deciding when to initiate HAART. Certain guidelines recommend starting treatment if the viral load is greater than 100000 copies $/ \mathrm{ml}$, unless the patient has been recently infected and has not yet reached a viral setpoint.

- It is a measure of viral response to therapy. An acceptable response to therapy is considered to be:

- a viral load reduction of more than 1 log from the baseline value after 6-8 weeks of therapy.

- a viral load of 5000 copies or less after 12 weeks of therapy.

- a viral load below detection limit of the assay after 12-24 weeks of therapy.

- It is an indicator of the development of viral resistance to therapy:

- Primary failure of therapy is indicated by a viral load that does 
not decrease as expected after initiation of HAART.

- Secondary failure of therapy refers to an increase in the viral load of 1 log or greater on two separate specimens at least two weeks apart after an initial adequate response to HAART ${ }^{13}$, 14,15 .

It must be noted that the HIV-1 viral load should not be used for the diagnosis of HIV-1 infection. This is because low false positive results (usually less than 2000 copies $/ \mathrm{ml}$ ) can occur with quantitative HIV-1 RNA testing. Such results can lead to confusion and misdiagnosis.

A viral load result below the assays lower detection limit (LDL) may be due to:

- effective HAART.

- lack of HIV-1 infection. Check the patient's HIV status.

- failure of the assay to detect the patient's variant of HIV. Commercially available HIV1 viral load assays detect only HIV-1 and not HIV-2. Most assays do not detect all variants of HIV-1.

The HIV-1 viral load must always be correlated with the patient's clinical picture and CD4+ T lymphocyte count.

\section{CD4+ T lymphocyte count}

For completeness, a mention must be made of the CD4+ T lymphocyte count. The CD4+ T lymphocyte count declines with acute infection. Once the viral load has reached its setpoint, the CD4+ T lymphocyte level increases, but rarely returns to pre-infection levels. As the immune system becomes exhausted, the CD4+ $\mathrm{T}$ lymphocyte count begins to decrease.

There are a number of different guidelines available recommending when to start HAART. The World Health
Organisation recommends initiating HAART when the CD4+ T lymphocyte count is less than 200 cells $/ \mathrm{ml}$ or higher if the patient has an AIDS-defining illness. The South African National Antiretroviral Treatment Guidelines agree with the WHO. The Southern African HIV Clinicians Society recommends initiating HAART as above, but also advises initiation if the CD4+ $T$ lymphocyte count is $200-350$ and has been shown to be decreasing rapidly. North American and European Guidelines offer HAART for CD4+ T lymphocyte counts less than 350 cells/ $\mathrm{ml}^{16}$.

The CD4+ $\mathrm{T}$ lymphocyte count should be tested after diagnosis of HIV infection. If HAART is not yet indicated, the CD4+ $T$ lymphocyte count should be repeated every 3-6 months. Once on treatment, the CD4+ T lymphocyte count should be monitored every 6 months.

A patient requiring HAART should be managed by a medical practitioner with experience in the care of patients with HIV.

\section{(P) This article has been peer reviewed}

\section{References}

1. UNAIDS/WHO AIDS Epidemic Update: Global Summary of the AIDS Epidemic Dec 2005. http://www.unaids.org/epi/ 2005/doc/report; accessed 6 April 2006.

2. UNAIDS/WHO AIDS Epidemic Update: Sub-Saharan Africa Dec 2005. http: //www.unaids.org/epi/2005/doc/report; accessed 6 April 2006.

3. Geretti AM. HIV-1 subtypes: epidemiology and significance for HIV management. Curr Opin Infect Dis 2006, 19: $1-7$.

4. Linal ML, Fan H, Hahn B, Lwer R, Neil $J$, Quackenbush $S$ et al. The reverse transcribing DNA and RNA viruses. In: Fauquet CM, Mayo MA, Maniloff $\mathrm{J}$, Desselberger U, Ball LA, editors. Virus Taxonomy. $8^{\text {th }}$ Report. California: Elsevier Academic Press; 2005. p421-436.
5. Wei X, Ghosh SK, Taylor ME. Viral dynamics in Human Immunodeficiency Virus type 1 infection. Nature 1993, 373: 117-122.

6. Busch MP, Satten GA. Time course of viraemia and antibody seroconversion following human immunodeficiency virus exposure. Am J Med 1997, 102(suppl.5B); 117-24.

7. Duong Ly $\mathrm{T}$, Laerche S, Brennan $\mathrm{C}$ Vallari $A$, Ebel $A$, Hunt $J$ et al. Evaluation of the sensitivity and specificity of six HIV combined p24 antigen and antibody assays. J Viro Met 2004, 122: 185-194.

8. Hecht FM, Busch FM, Rawal B, Webb $\mathrm{M}$, Rosenberg E, Swanson $\mathrm{M}$ et al. Use of laboratory tests and clinical symptoms for identification of primary HIV infection. AIDS 2002, 16: 1119-1129.

9. England K, Thorne C, Newell M. Vertically acquired paediatric coinfection with HIV and hepatitis $C$ virus. Lancet Infect Dis 2006, 6: 83-90.

10. South African Department of Health Guidelines for the Management of HIV-Infected Children 2005. http:// www.doh.gov.za/docs/policy; accessed 10 April 2006.

11. Newell ML, Loveday C, Dunn D, Kaye $\mathrm{S}$, Tedder R, Peckham $\mathrm{C}$ et al. Use of Polymerase Chain Reaction and quantitative antibody tests in children born to human immunodeficiency-1 infected mothers. J Med Virol 1995 Dec, 47; 4: 330-335.

12. Giles RE, Perry KR, Parry JV. Simple/ rapid test devices for anti-HIV screening: Do they come up to the mark? J Med Virol 1999 Sept, 59; 1:104-109.

13. Powderly WG, Saag MS, Chapman S, Yu G, Quant B, Clendeninn NJ. Predictors of optimal virological response to potent antiretroviral therapy. AIDS 1999 Oct 1, 13; 14:1873-80.

14. Spencer D. The Clinical Practice of HIV Medicine. Goldstream Publishers. Johannesburg 2005, p 4-30.

15. National Department of Health. Antiretroviral Therapy in Adults. National Antiretroviral Therapy Guidelines $1^{\text {st }}$ ed. 2004. http://www.doh.gov.za/docs/ factsheets; accessed April 6, 2006.

16. Adult Guidelines Committee. Southern African HIV Clinicians Society. Antiretroviral therapy in adults. South Af J HIV Med 2002, 8:22-29. 